\title{
BUILDING CREATIVITY: AN ARGUMENT FOR THE REFORMULATION OF BRAZIL'S COPYRIGHT SYSTEM
}

\section{Eduardo Magrani}

eduardomagrani@gmail.com Institute for Technology and Society of Rio de Janeiro - ITS, Rio de Janeiro, Rio de Janeiro, Brazil.

\section{Helena Ferreira Matos}

helenaferreiramatos@gmail.com Harvard Law School - HLS,

Cambridge, Massachusetts, USA.

\begin{abstract}
Brazil has had a history of maximization of copyrights since the first rules prohibiting unauthorized uses of intellectual works emerged in the first half of the nineteenth century. The country's current system of exceptions and limitations is not adequate to the current times, and has been applied in a restrictive manner. This has created an environment that is overly hostile to the use of works that would otherwise be considered fair, and hampers the development of a thriving creative economy. With this in mind, the reinterpretation of the norms regarding copyrights, as well as the reform of Copyright Law is requested.
\end{abstract}

Keywords: Copyrights, Creative Economy, Fair use, Exceptions and limitations to copyrights 


\section{COPYRIGHT LAW IN BRAZIL}

The history of author rights in Brazil has been marked by a great expansion of the protection granted to the creators of artistic works, often to the detriment of the general public. The first regulation in the country regarding this topic arose with the creation of Law courses in Olinda and São Paulo in 1827. The legislation that established these courses attributed to the professors the exclusive rights over whichever courses they published for a period of ten years (art. 7).

Four years later, the Criminal Code of the Empire, in its article 261, indirectly created the right of reproduction of an artistic work, by instituting the prohibition of unauthorized reproduction of written or printed works composed or translated by Brazilian citizens (Mizukami, 2007). The protection awarded to these works lasted for the entire life of the author and ten more years after his or her death, if there were heirs (art. 261). In 1890, the new Penal Code also contained provisions regarding the "violation of literary and scientific property rights", between articles 342 and 344 (Mizukami, 2007). At the time, laws, decrees, resolutions, regulations, reports and any other publications by both the Legislative or Executive powers were awarded protection. The duration of the protection granted was not altered from the previous Penal Code, and lasted until ten years after the death of the author. An innovation brought by this new legislation were copyrights regarding translations: unauthorized translations were, from then on, prohibited, although it remained possible to make a partial quote of any written work, if it was used for criticism, debate or teaching (Mizukami, 2008). Furthermore, article 348 also defined as a crime the unauthorized execution or representation of musical works, tragedies, dramas, comedies or any other productions held at theaters or as public spectacles.

It is therefore clear that copyright protection in Brazil, including the establishment of its exceptions and limitations, first emerged with criminal law. The first piece of civil Legislation for the protection of author rights passed in Brazil was the Medeiros Albuquerque Law (Law no. 496/1898). The main change was that it altered the length of copyright protection awarded to the authors, to last until fifty years after the first day of January of the publication year (art. 3). Moreover, it instituted the prohibition of unauthorized modifications to artistic works, even those already in the public domain or simply not under legal protection. Copyrights were only granted if the work was deposited in the National Library in until two years after publication (art. 13). There was also a temporal limitation to the author's rights to make or authorize translations, representations or executions of the works, fixed in ten years (art. 3, par. 2).

The main feature of the new legislation for copyrights was the introduction of the limitations to author rights. Article
$22^{1}$ of the Medeiros Albuquerque Law brought seven restrictions in regard to the protection of authors' rights, tipping the balance more towards freedom of expression and access to information.

The 1916 Civil Code substituted the Medeiros e Albuquerque Law, although it was clearly inspired by its provisions. Copyrights were now granted for a period of sixty years after the author's death (art. 649). The new Legislation established ten types of limitations to author rights (Mizukami, 2007), and also instituted some formal requirements for their recognition, such as the deposit of the work. However, the law no. $5.988 / 73$ specified that it was an option for the author to register his or her work, rather than a necessity. The term for copyright protection was extended to encompass the author's life and his or her successors', if they were his or her children, parents or spouses; or the author's life plus sixty more years, if there were other kinds of heirs (art. 42). Cinematographic, phonographic, photographic and other works of applied arts were awarded protection for 60 years, from the first day of January of the year following their completion (Mizukami, 2007).

In 1998, Brazil passed the Law no. 9.610, which still regulates copyright protection in the country. It introduced several modifications to the previous legal regulation of copyrights, and it maximized author's rights. There were several new restrictions imposed to the types of limitations established, for example, the prohibition of making private copies utilizing more than "small excerpts" of a work, the expansion of the term for protection (articles 41 and 96), the

1 "Art. 22. It is not considered counterfeit: 1) the reproduction of passages or small parts of works already published, or the insertion, even full, of small texts in the body of a larger work, as long as it has a scientific character or is a compilation of texts of several writers, composed for use of public instruction. In no case could reproduction take place without the citation of the work from which it is extracted and of the author's name; 2) the reproduction in newspapers and periodicals of news and political articles extracted from other newspapers and periodicals, and the reproduction of speeches pronounced in public meetings, of whatever nature. In the transcription of articles there should be the mention of the journal from where they are extracted and the name of the author. The author, however, either of the articles, whatever their nature, or the speeches, is the only one that could print them separately; 3 ) the reproduction of all official acts of the Union, the States or the Municipalities; 4) the reproduction in books or journals of passages of any work with a critical end or controversy; 5 ) the reproduction in the body of a text of works of figurative arts, provided that this is the main text, but it is obligatory to cite the author's name; 6 ) the reproduction of works of art found in the streets and squares; 7) the reproduction of portraits or busts of private order, when it is made by the owner of the objects ordered "(translated by the author). 
protection awarded to databases (article 87 ) and provisions regarding the violation of TPMs (technological protection measures) and DRM (Digital rights management) systems (article 107).

This legislation awarded protection to copyrighted works even greater than required by the TRIPS agreement, of which Brazil is signatory. This demonstrates the maximalist approach to copyright protection developed in the Brazilian legal system since its introduction. In response to this tradition, which tends to hamper freedom of expression and access to information, the creation of a new framework for this area has been discussed, as a way to make the law more compatible to the new uses and needs of Brazilian society.

\section{EXCEPTIONS AND LIMITATIONS IN CURRENT COPYRIGHT LAW}

There is a system in the Law no. 9.610 which establishes explicit limitations to copyrights, which can be divided into intrinsic or extrinsic restrictions. The first group is composed by vertical and horizontal limitations. Vertical limitations establish a term for copyright protection, while horizontal limitations are independent of any time limit and reflect the interests and necessities of the community (Souza, 2006).

The Brazilian Copyright Law explicitly determines, in its chapter IV (articles 46-48) ${ }^{2}$ some horizontal limitations to

2 "Art. 46. Does not constitute copyright infringement:

I - the reproduction: a) in the daily or periodical press, be it news or an informative article, published in journals or periodicals, with the mention of the author's name, if subscribed, and the publication from where they were transcribed;

b) in journals or periodicals, of speeches pronounced in public meetings of any nature;

c) of portraits or other form of representation of the image, made to order, when performed by the owner of the object ordered, without the opposition of the person represented in them or their heirs;

d) of literary, artistic or scientific works, for the exclusive use of the visually impaired, where the non-commercial reproduction is made by the Braille system or other procedure on any medium for those receivers;

II - the reproduction, in a single copy of short excerpts, for the private use of the copyist, provided it is made by the latter, with no intention of profit;

III - citation in books, journals, magazines or any other means of communication, of passages of any work, for purposes of study, criticism or controversy, to the extent justified for the purpose to be achieved, indicating the name of the author and the origin of the work;

IV - the collection of lessons in educational establishments by those to whom they are addressed, forbidden its publication, in author rights, by defining some circumstances in which the authorization is not needed for the use of a work. The vertical limitations are established in articles $41-45^{3}$.

whole or in part, without the prior and express authorization of the person who gave them;

$\mathrm{V}$ - the use of literary, artistic or scientific works, phonograms and radio and television broadcasting in commercial establishments, solely for the purpose of demonstrating to the public, provided that those establishments market the supports or equipment enabling them to be used;

$\mathrm{VI}$ - theatrical and musical performance, when performed in the family recess or, for exclusively didactic purposes, in educational establishments, and without any profit intention;

VII - the use of literary, artistic or scientific works to produce judicial or administrative evidence;

VIII - the reproduction, in any works, of small stretches of pre-existing works, of any nature, or of integral works, in the case of plastic arts, where reproduction itself is not the main objective of the new work and does not harm the normal exploitation of the work reproduced or cause unjustified damage to the legitimate interests of the authors.

Art. 47. Paraphrases and parodies that neither are true reproductions of the original work nor imply disrepute are permitted. Art. 48. Works permanently located in public places may be represented freely by means of paintings, drawings, photographs and audiovisual procedures "(translated by author).

3 "Art. 41. The patrimonial rights of the author remain for seventy years counted from January 1 of the year subsequent to the one of his death, obeying the order of succession of the civil law. Sole paragraph: Applied to the posthumous works the term of protection to which the caput of this article alludes.

Art. 42. When the literary, artistic or scientific work carried out in co-authorship is indivisible, the period provided for in the previous article shall be counted from the death of the last of the surviving co-authors.

Sole paragraph: The rights of the co-author who dies without successors shall be added to those of the survivors.

Art. 43. The term of protection of the patrimonial rights on anonymous or pseudonymous works will be of seventy years, counted from January 1 st of the year immediately after the first publication.

Sole paragraph: The provisions of art. 41 and its sole paragraph should be applied whenever the author makes himself known before the expiration of the period established in the caput of this article.

Art. 44. The term of protection for the patrimonial rights on audiovisual and photographic works will be of seventy years, starting from January 1 of the year following the one of its disclosure.

Art. 45. In addition to the works in respect of which the term of protection of the patrimonial rights has elapsed, they belong to public domain:

I - those of deceased authors who have not left successors;

II - those of unknown author, except for the legal protection of 
The intrinsic horizontal limitations to copyrights include: (i) the reproduction of works and public speeches for information purposes in the press, (ii) the representation of images on demand, (iii) the non-profitable adaptation of works for the visually impaired, (iv) the single partial copy, for private, non-profitable use by an individual, (v) citations, (vi) a collection of educational activities for their own use, (vii) the use of works for demonstrating electronic products, (viii) the non-profitable theatrical representation or musical execution for educational purposes or in family relations, (ix) presentation of judicial or administrative evidence, $(x)$ use of small excerpts in new works, which are not the essential focus of the new work and do not hamper the normal exploration of the reproduced work.

Yet these intrinsic horizontal limitations to authors' rights generate some difficult interpretation problems and do not represent the interests of the community in a way that is satisfactory. For example, current legislation limits private copies to small excerpts of the work, and does not determine the purposes that are allowed. This leads, unfortunately, to many fair uses of works being prohibited, such as the case with academic research and other educational scopes. There is a clear contrast with the previous legislation, which allowed the private single copy of any work, as long as it was not intended for profit.

Therefore, a pattern of maximization of author rights is still very noticeable in current Copyright legislation. In fact, it is not even allowed that someone makes a private copy of a work for personal non-profitable use, or even for educational, teaching or research purposes. Of course, that has a significant impact for students and researchers, who depend on the access to other works to develop their activities.

This provision is criticized for many reasons. First, it is almost impossible to monitor if works are being copied for those reasons. Moreover, it is certainly illogical and unreasonable to demand that scholars buy every single piece of material they need to read to produce content. There is also the problem with the undefined expression "small excerpts". This has been object of strong controversy, as it is not clear what constitutes a small excerpt or what would surpass that. In fact, many institutions have enacted resolutions to try and define the scale for that determination. Even some draft legislation has been proposed to try and establish a more definitive frame for that provision ${ }^{4}$.

ethnic and traditional knowledge "(translated by author).

4 Senate Bill No. 131, 2006, authored by Senator Valdir Raupp, which seeks to amend section II of art. 46 of Law No. 9,610 of February 19, 1998, with the purpose of establishing limits for reproduction of work, as well as Bill 4266/2004 authored by Councilman Júlio Lopes, which prohibits the use of machines for reproduction of textbooks in higher education establishments.
According to the Brazilian Association for Reprographic Rights (Associação Brasileira de Direitos Reprográficos - ABDR) manual, the expression "small excerpts" means a "fragment of the work that does not contemplate its substance. A small excerpt does not refer to the extent of the reproduction, but to the reproduced content. Thus, any intention to associate the small excerpt with $10 \%$ or $15 \%$ of the totality of an integral work is unrealistic. This is because it is possible that in $10 \%$ or $15 \%$ of the reproduction a substantial part of the work is contemplated (Carboni, 2007). Actually, what should be considered for authorization of reproduction should not be the extent of the copy or the excerpt used, but how that reproduction is employed. Since there is not any legal provision which establishes a percentage of what would be acceptable for the reproduction of copyrighted works, to institute a rule that incorporates a percentage for that purpose would not be in accordance with the Brazilian legal system.

The debate surrounding the potential enactment of new copyright legislation in the country encounters strong opposition from institutions that defend author rights, which tend to argue in favor of the enforcement of more restrictive rules regarding the unauthorized reproduction of protected works. On this topic, Guilherme Carboni (2007) states the following:

(...) copyright now masks the fact that it functions as a powerful tool for the entertainment and information industry and not the author, who sees himself under the condition that he has to give up his rights in favor of this Industry, so that it can profit from the commercialization of his work.

(...) The result is the perversion of the law to favor merely corporatist interests, since the law does not establish quantitative limitations. Some educational institutions even banned the copying of books and handouts to avoid problems. It is not only the students, researchers or scientists who lose out on it, but, ultimately, the country.

As stated previously, the extent of the restrictions imposed on the unauthorized reproduction of works has an especially detrimental effect on the academic environment. First, students argue that it would be impossible to attain all the bibliography recommended by professors, because they are usually expensive and in great quantity. Second, there are many books that are unavailable for purchase, because they are older or simply have not been reprinted by editors. These copies are usually held by libraries in universities, and should be easily accessible to all the students (Mizukami, 2008). 
Brazilian Journal of Operations \& Production Management

Volume 15, Número 3, 2018, pp. 366-375

DOI: 10.14488/BJOPM.2018.v15.n3.a3
Although the list of limitations to author rights does not necessarily consider this element, the evaluation of what is allowed and what is prohibited often derives from determining whether the reproduction of a work was intended for commercial or non-commercial purposes. Brazilian culture seems to have also adopted this as a common way of thinking. There appears to be a trend in public opinion that believes in a sort of right to use works in a non-commercial way, which strongly rejects the stance widely defended by entertainment and information industries that sharing content should be prohibited even if it is intended for private, non-commercial use (Mizukami, 2008).

The enforcement of a more restrictive interpretation of limitations on author rights has also constrained some other uses that should be considered legal, such as time shifting ${ }^{5}$. The list of limitations on copyrights does not explicitly states the motives for those provisions, which makes it more difficult to establish further legal uses that are not strictly contained in that catalogue. In contrast, the treatment given by the Brazilian legal system to industrial rights clearly states the foundations to its limitations in article 5, section XXIX of the Constitution. The application of industrial property legislation should respect the social interest and the technological and economic advancement of the country (Carboni, 2007).

Some believe the alterations brought to the Brazilian Penal Code in 2003 also introduced, by accident, a new type of limitation to author rights. This "mistake" is easily explained by the fact that legislators based the bill on the 1973 version of the Copyright Legislation, which permitted the full copy of a work (Mizukami, 2008). In this sense, the Penal Code states in its article 184 , paragraph $4^{\text {th }}$ :

Paragraphs 1, 2 and 3 do not apply in the case of an exception or limitation to copyright or those related thereto, in accordance with Law No. 9.610 of February 19, 1998, nor the Copy of an intellectual work or phonogram, in a single copy, for the private use of the copyist, with no intent of direct or indirect profit. (Included by Law No. 10,695 of July 2003)

This provision seems to have substituted the more restrictive determination of the 1998 Copyright Law, by the chronological criterion of lex posterior derogat priori (Decreto Lei $4.707 / 42$, art. 2,1 ). In this case, it would be a mistake to apply the principle that states that specific legislation prevails over the more generic norms, since both of the provisions deal specifically with copyright (Mizukami, 2008). Thus, it is our understanding that the best meaning attribut-

5 Time shifting means the recording of programs to be watched at a later moment. ed to this piece of legislation reestablishes the previous limitation to author rights, allowing the single full copy of any intellectual work without commercial purposes.

Also section IV of article 46 of the Brazilian Copyright Law can be criticized for the way it was formulated. It is obvious that students are allowed to take notes during a class; however, it appears that the purpose of the provision was to reiterate rights held by professors to exert control over how these notes are used (if they are displayed, commercialized, etc.)(Mizukami, 2008).

Furthermore, the legislation for Copyrights is also dated in regard to the use of new communication and media technologies. Article 46, section I, lines "a" and " $b$ " mention "daily or periodic press", seemingly considering only written press (Carboni, 2007). However, most of the news that are produced and distributed is routed through diverse channels, such as the Internet or the television. In the current digital age, it is clearly inadequate to speak of a "daily or periodic press".

These stipulations show a trend in Brazilian legislation that favors author rights in detriment of fair uses of intellectual works. The Digital Age brought great innovations and new ways of producing, reproducing, and modifying artistic content, that is, activities that heavily impact copyright laws. The restrictive limitations to copyrights imposed by the 1988 bill and the traditional view that awards greater protection to authors are not in harmony with the current makeup of the digital environment. Web 2.0, mash-ups, peer production and remix culture are important aspects of the contemporary production of content and should not be hampered by excessively big restrictions on limitations to author rights.

In countries where the droit d'auteur tradition is strongest, the restrictions on derivative works tend to be even more intense, because of the prevalence of the personality theory of copyright, which defends the existence of some "moral rights" of the author, including a "right of integrity". The idea behind this protection is the fear that the alteration of a work may be prejudicial to the original author's reputation or personality. This is made clear by the provision regarding parodies and paraphrases on article 47 . Although these two forms of derivative works are permitted, there is one crucial condition for that acknowledgement: they cannot damage the credit of the parodied work. However, since parodies usually do try to taint the image of an original work in some way, it seems contradictory that the law should make the authorization with that kind of reservation (Mizukami, 2008).

Regarding the interpretation and execution rights, article 46 establishes: 
Art. 46. It does not constitute an offense against copyright:

$\mathrm{V}$ - the use of literary, artistic or scientific works, phonograms and radio and television broadcasting in commercial establishments, exclusively for demonstration to the clientele, provided that those establishments market the supports or equipment that allow their use;

$\mathrm{VI}$ - theatrical performance and musical performance, when performed in the family recess or for exclusively didactic purposes in educational establishments, and in no case with intent to profit.

These restrictions on author rights are clearly insufficient. For instance, the public execution of musical excerpts is still forbidden without authorization from the original creator, even if it was executed in perfect accordance to the rules established in article 46, sections III and VIII of the Copyright Law. Moreover, the execution of works containing parts of other musical compositions is also prohibited, even if it is done for purposes of study, critic or discussion, and regardless of it not causing any harm to the normal exploration of the reproduced work or to the interests of the original authors.

For these reasons, the Brazilian Copyright Law is considered one of the most restrictive bills of the world in this matter. The maximization of author rights and extensive restrictions on the limitations to copyrights have made it so that the national policy on copyright seems to overlook the fair uses of intellectual works and the importance of granting access to these works to the community.

In this sense, even some more flexible provisions established by the Bern Convention and the TRIPS agreement have not been adopted by the Brazilian Copyright Law. For example, article 9 (2) of the Bern Convention does not mention the prohibition to integral copies of the work protected by copyright law. The legislation in Brazil, however, goes beyond the international norms in permitting only the reproduction of small excerpts, even if they are used solely in a private and familial context.

Therefore, while the Bern Convention has a clear purpose of broadening the possibilities for the use of protected works, to promote access to knowledge and the fundamental right to education, Brazilian Legislation appears to have somewhat neglected those objectives, unduly restricting the reproduction of copyrighted works. In fact, article 10 (2) of the Bern Convention ${ }^{6}$ does not impose a limit to the extent

6 Article 10 (2) of the Berne Convention states: "(2) It shall be a matter for legislation in the countries of the Union, and for special agreements existing or to be concluded between them, to of the authorized use, which means that the integral reproduction of a work can be allowed, if it is based on a fair use.

Undeniably, the production of artistic and intellectual works throughout history has depended on the gradual and growing distribution of knowledge. It is clear, then, that Brazilian Legislation, the way it is currently established, does not provide the adequate means for promoting the broader creation of new content. Therefore, it is necessary to expand the access to intellectual works in order to promote more creative communities.

\section{THE CONSTITUTIONAL REINTERPRETATION OF THE COPYRIGHT LEGISLATION AND THE PROPOSAL TO REFORM BRAZILIAN COPYRIGHT LEGISLATION}

As stated above, the parameters established by the Copyright Legislation need to be revised and reinterpreted in consonance with fundamental rights protected by the Constitution, especially regarding its application to cases of private use. $^{7}$

We argue that, in many cases, the interests of the public should prevail over the individual interests of the author. With this in mind, we propose some alternatives to the restrictive nature of the current Copyright Law.

Copyright protection has two main functions: promotion$\mathrm{al}^{8}$ and social. The first one refers to the concession given to the author to temporarily explore, in an exclusive manner, his or her work, and in turn encourage the new additions to that country's cultural assets. On the other hand, the social function guarantees access to the works for the public, which serves to inspire the creation of other new works and contribute to the cultural development of the country (Pereira de Souza, 2009).

With this in mind, the social function of copyrights should also be considered for establishing its limitations. The lack of debate in the academic community about the reasons why those limitations are defined leads to less accurate and less predictable results in determining which uses are allowed and which are prohibited, and gave way to overly restrictive interpretations of those uses. Furthermore, it enables the entertainment industry to push for a stronger protection

permit the utilization, to the extent justified by the purpose, of literary or artistic works by way of illustration in publications, broadcasts or sound or visual recordings for teaching, provided such utilization is compatible with fair practice."

7 On the constitutional interpretation of legislation, see Tepedino, (2001).

8 The word "promotional" is used because of the system offering advantages to stimulate the creation of content. 
Brazilian Journal of Operations \& Production Management

Volume 15, Número 3, 2018, pp. 366-375

DOI: 10.14488/BJOPM.2018.v15.n3.a3 of author rights and for more severe penal sanctions for infringement (Mizukami, 2008). However, these characteristics have created a very hostile environment for common people who try to use artistic or scientific content. A great number of people might unwittingly infringe copyrights daily, often with common, private uses, which not always constitute bad-faith. In fact, these practices generally involve the production of new works or allow access to culture.

Beyond the constitutional reinterpretation, other partial solutions to the friction caused by the use of works by other people are legal reform, the request for authorization for use to the owners of copyrights or the licensing of works by establishing public licenses. The first of those three is already under debate, and is indispensable for a better regulation of copyrights. The second is not viable or efficient, because of the amount of bureaucracy it tends to entail, which is incompatible with the need for rapid trades and exchanges that characterize present times. The third has been discussed as a possible alternative to the conflicts mentioned.

Because of these problems, new ideas about the creation of a type of prior authorization, enabled by technological advances, have emerged. One of them are the so called General Public Licenses (GPLs), employed by the free software developer community and by the Creative Commons project. By adopting this type of license, authors give up parts of their rights as copyright owners in favor of the community, without renouncing their status as owner. This position characterizes a form of social solution to the Laws restrictive attributes.

The "free" nature of the license is derived from the embedded prior authorization to use, copy, modify or distribute the work, as part of an atypical licensing contract. Consequently, this practice brings about greater access from the public to intellectual works, a much more practical way of receiving and granting authorizations and higher security for the users.

The Creative Commons licenses are a type of public licensing ${ }^{9}$ in which the limitations to the uses of the work are previously established. This fact helps generate greater security for the users of other works and promotes cultural development.

9 Creative commons licenses have emerged from the concept of General Public Licenses. Relevant in this regard are comments by Sérgio Branco and Pedro Paranaguá: "It should be noted that for all intents and purposes there is no difference between the GNU-GPL license of Creative Commnons (CC-GNU-GPL) and GNU- Traditional LPG. Therefore, the terms GNU-GPL and CCGNU-GPL thus have interchangeable meaning." (Branco et Paranaguá, 2009).
This is one example of an instrument which helps understand Copyrights in the way the Constitution intended their purposes to be constructed: as a system which encourages the artistic and scientific creativity, as a means to promote a richer and more plural culture in society, in which everyone is given the right to access its assets. This way, a greater value is granted to the principles of freedom of expression and access to information. These benefits to the community should not be treated as an exception, but as the rule regarding the regulation of uses of intellectual works.

In January 2010, the Public Domain Manifesto was launched, elaborated in the context of the activities developed by the COMMUNIA Project ${ }^{10}$, and was translated by the Center for Technology and Society - CTS/FGV, and by the Ministry of Culture. The objective was to advocate for a less individualist position regarding the protection of author rights, by supporting the mechanisms that allow for a greater access to culture. In this sense, the public domain plays a crucial role in the promotion of cultural participation and digital innovation.

The Manifesto not only values the commons - works not awarded copyright protection or works for which that protection has expired - but also the so called "voluntary commons", made so by public licensing tools. Moreover, the document establishes some general principles for Copyright policy: (i) treating public domain as a rule and the protection of author rights as an exception; (ii) reducing the term for copyright protection, which should last only the necessary time to reach a balance between social function and promotion of author rights; (iii) recognition of the voluntary renouncement of author rights and the sharing of protected works as legitimate exercise of the exclusivity awarded to author; and (iv) the exceptions and limitations to author rights and the fair use regimes should be actively supported to guarantee the effectiveness of the fundamental balance between author rights and the public interest. ${ }^{11}$

The Manifesto defends a reasoning that is similar to what we seek to advocate in this paper. Access to cultural assets is essential to build a more plural and open society, and also encourages the production of new intellectual works. The principle of free use derives from the idea that the interests of the community should be balanced in a better way with the interests of the individual authors.

The Manifesto establishes some general recommendations for the treatment of Copyrights, each of which will be briefly explained.

10 The COMMUNIA Project is a network from the European Union on Public Domain.

11 See http://publicdomainmanifesto.org/. Accessed 28 July 2017. 
Brazilian Journal of Operations \& Production Management Volume 15, Número 3, 2018, pp. 366-375

DOI: 10.14488/BJOPM.2018.v15.n3.a3

\section{The term for the protection of author rights should be reduced}

The duration of the term for copyright protection of intellectual works is excessive. This fact, combined with the absence of formalities for their registration is absolutely incompatible with the pursuit of greater access for the public to shared knowledge and culture. The Bern convention determines protection to last until 50 years after the death of the author. ${ }^{12}$ That provision is in itself already too extensive, and Brazilian Legislation establishes an even bigger term, which proves absolutely unreasonable and inadequate to current times. Furthermore, it is responsible for the generation of "orphan works", that are neither in control of the author nor part of the public domain, which complicates even more the attempts at legally utilizing these works.

\section{Any change in the scope of copyright protection (including any new definition on the concept of protected works or the expansion of exclusive rights) needs to consider its effects on the public domain}

The economic rights of the author are only temporary limitations to the broader access to the work from the public. The public domain should be the rule, and the protection of author rights should in no case be extended retroactively to works that have already been held under that type of protection.

3. A work that has entered the structural public domain in its country of origin should be recognized as part of the structural public domain in all other countries

Following this reasoning, if a work is not protected by copyrights in a country, either because it falls under conditions that exclude this type of protection or because it is not original or the term for its protection has already ended, no one should be able to invoke author rights over that work in another country, thus removing that work from the structural public domain.

\section{Any false or misleading appropriation of public domain material should be legally punished.}

In order to preserve the integrity of the public domain and protect the users of the works in that sphere, any false or misleading attempts at claiming exclusivity over materials in the public domain should be declared illegal and sanctioned.

12 See article 7 (1) of the Berne Convention.
5. No other intellectual property right should be used to reconstitute the exclusivity over works in the public domain

Regulations external to copyrights should not be used to obtain exclusive control or reconstitute author rights over works that are in the public domains, since the preservation of this classification is essential to the internal balance of the system.

\section{There should be a practical and effective way of making available "orphan works" and published works not commercially available (such as depleted works) for reuse by society.}

Orphan works are those which are neither in control of their original authors nor in the public domain. In these cases, we defend that the possibility of productive reutilization of the works is beneficial in order to fulfill their social function. In that way, the use of those works could serve the promotional function of author rights and give value to the right of the public to access content.

\section{Institutions for the protection of cultural assets should play a special role in the efficient registration and conservation of works in the public domain.}

The organizations responsible for the protection of a country's cultural heritage are given the task to preserve the shared knowledge and culture of that society. Part of that should include, necessarily, the cataloguing, preservation and the provision of works in the public domain to be freely and easily accessed by the public.

8. There should be no legal obstacles that prevent the voluntary sharing of works or the allocation of works to the public domain.

If it is harder to voluntarily share intellectual works or give them up to the public domain than it is to keep author rights to the individual creator, the social function of copyrights is not respected. Both of these options of broadening access to a work constitute legitimate exercises of exclusive rights granted by Copyright law, and both are fundamental to guarantee the access to cultural assets and knowledge. Furthermore, it is a way to privilege the own author's will.

9. Personal and non-commercial use of protected works should generally be possible, and alternative ways of remuneration for the author should be explored. 
The private use of a work does not harm its commercial exploration by the owner of the copyrights; therefore, it should be considered fair use. In some situations, it is absolutely unreasonable to hold as illegal the private copying, such as when a legitimate owner of a book wants to reproduce it once for his or her individual use; when the acquisition of some works is impossible because a work is depleted; when it comes to the so called "orphan works"; when it entails a mere alteration of the format of a work; or when the copying is intended to preserve the contents of the original work. The permission of those uses is essential to stimulate the creation of an adequate policy for national development.

Thus, rediscovering the public domain is of utmost importance in trying to rebalance author and social interests. It serves not only for the development of the country's creative economy, but also plays a crucial role in several areas, such as education, science, culture, and information for the public sector.

Beyond the legal reform, the establishment of the constitutional principles that are the bases for the definition of the exceptions and limitations to copyrights help guide a new interpretation of the law. This is a short term solution to enable the restoration of a better balance between the interests of authors and those of the community.

Considering the principle of the social function of copyrights, some otherwise unlawful acts could be defended, such as (i) the copy for the preservation of the original work; (ii) the representation and execution of the work in full in educational institutions; (iii) the private copy of a legally acquired work; and (iv) the representation and execution of works in a private environment. The permission of these activities would signify the partial prevalence of the social function of author rights over their promotional function.

Article 5, sections IX and XIV and article 215 of the Constitution also have a direct connection to the treatment of copyrights, protecting freedom of expression, access to information, and the exercise of cultural rights, while defending State actions with the purpose of valuing Brazilian cultural assets, the diffusion of those assets, democratization of the access to culture and the recognition of ethnical and regional diversity.

The prohibition to several forms of manifestations derived from an original work represents a restriction in terms of freedom of expression. As the protection to author rights increases, decreases the degree of freedom of the community to express itself based on or merely regarding that work (Carboni, 2007).

However, the greatest impact of author rights on the fundamental rights protected by the Constitution regards the right to access information. In current society, characterized by the fast and intense exchange of information through the use of various means, including the Internet, there is a great demand for access to knowledge and art, and for the freedom to create new content. Using this principle, the law can be reinterpreted to admit more types of uses as fair uses of a work.

With the reinterpretation of Copyright legislation, social interests represent extrinsic limitations to author rights, by establishing circumstances in which these rights do not warrant the prohibition of the use of a work.

Copyrights should be seen as part of the constitutional system which seeks to stimulate cultural development. Thus, author rights should be considered an exception to public domain, and not the other way around. As such, they should not induce an overly restrictive interpretation of their exceptions and limitations, which should be expanded with the application of the extrinsic factors described above. The applicator of the law should balance the differing interests defended by the Constitution, and harmonize the tensions between norms, considering them as part of a logical, unitary and coherent body of rules and principles (Canotilho, 1998).

The reform of the current Copyright Law is necessary, and could bring many benefits to the community. However, it should not be seen as the only means of promoting the values that should be defended in regard to the creation and protection of artistic and scientific works.

The reform is still under debate; however, the idea is to transform the copyright protection system into an instrument for the development and consolidation of the economy and culture in the country, while ensuring that the constitutional rights of the authors and the public are respected. In this line of thinking, Alexandre Libório also defends (2008):

Copyright is not an "isolated island" in the legal order in terms of its "natural" values being able to nullify or prevail over any others. Thus, although such "natural values" serve as a precondition and limit of legal regimes, the legislator must be given a wide margin of freedom to shape these regimes according to the economic and social aims that he intends to achieve, namely the reduction of asymmetries of information, taking into account other competing values such as freedom of information and criticism, promotion of science and education and access to culture (...).

The Ministry of Culture in Brazil has given several justifications for the necessity of the Copyright reform, such as ex- 
panding and ensuring the effective stimulus and protection to authors and their creations; promoting the equilibrium of rights between all involved; broadening the population's access to assets and cultural services and making them more democratic processes; adapting the legislation to the new paradigms established by the digital environment and enabling State action in the creation of public policies for the promotion, supervision, regulation and defense of the interests of society internally and of the country in the international community.

\section{CONCLUSION}

The current legislation that protects author rights in Brazil bases itself, first and foremost, in the protection of the authors' economic rights. This has created a disharmony between the defense of the individual rights to explore an intellectual work and the promotion of public interest, which is enabled by the public domain and the system of exceptions and limitations to copyrights.

The solution to the imbalance that exists between these two spheres (the public interest and the interests of the individual owners of copyrights) involves multiple actions, including the constitutional reinterpretation and reform of the Copyright Law and the use of other social solutions, such as the utilization of General Public Licenses.

The main goal is to prevent that intellectual property rights end up engulfing individual and social rights guaranteed by the constitution. To avoid that, it is necessary to reestablish a better balance between the values in conflict. Considering the current state of things, this goal will only be reached with the adoption of an ampler view of the exceptions and limitations to author rights. In fact, the excessive protection awarded to works may even work against the author's best interests, as, in many cases, the ones who profit the most from the economic exploration of these creations are the intermediaries of the industry.
This debate is especially important now, in a moment where the digital environment is expanding. Society, its representatives and the applicators of the Law should seek the best ways to balance the interests at stake, in a way that helps promote fundamental rights and the pursuit of the main goals for the development of the country.

\section{REFERENCES}

Mizukami, P. (2007), Função Social da Propriedade Intelectual: Compartilhamento de arquivos e Direitos Autorais na CF/88, Pontifícia Universidade Católica de São Paulo, 2007. Tese (Mestrado), São Paulo.

Mizukami, P. et al. (2008), "Exceptions and Limitations to Copyright in Brazil: A call for Reform", in Shaver, L. (org.), Access to Knowledge in Brazil: New Research on Intellectual Property, Innovation and Development, Yale Law School Press, New Haven.

Souza, A. (2006), A função social dos direitos autorais: uma interpretação civil-constitucional dos limites da proteção jurídica, 1. ed., Faculdade de Direito de Campos, Campos dos Goytacazes.

Carboni, G. (2007), “O Direito de Autor e seus Desafios: Os Conflitos com a Liberdade de Expressão, o Direito de Acesso ao Conhecimento, à Informação e à Cultura e o Direito ao Desenvolvimento Tecnológico", in Reis, R. et al. Propriedade Intelectual: agricultura, software, direito de autor, medicamentos: interfaces e desafios, 1. ed., ABIA, Rio de Janeiro, RJ.

Tepedino, G. (2001), Problemas de Direito Constitucional. 2. ed., Renovar, Rio de Janeiro, RJ.

Pereira de Souza, C. (2009), O Abuso do Direito Autoral, Tese (Doutorado) - Universidade do Estado do Rio de Janeiro, Faculdade de Direito.

Paranaguá, P. et Branco, S. (2009), Direitos Autorais. FGV, Rio de Janeiro, RJ.

Canotilho, J. (1998), Direito Constitucional e teoria da Constituição. 7. ed., Almedina, Coimbra.

Pereira, A. (2008), Direitos de Autor e Liberdade de Informação, Almedina, Coimbra.

Received: 30 Jul 2017

Approved: 11 Jun 2018

DOI: 10.14488/BJOPM.2018.v15.n3.a3

How to cite: Magrani, E,; Matos, H. F. (2018), "Building creativity: an argument for the reformulation of Brazil's Copyright system", Brazilian Journal of Operations \& Production Management, Vol. 15, No. 3, pp. 366-375, available from: https://bjopm.emnuvens.com.br/bjopm/article/view/376 (access year month day). 